\title{
Barriers to Innovation within SMEs in the Lebanese Food Industrial Sector
}

\author{
Nisreen Abi-Farraj
}

\begin{abstract}
The purpose of this paper is to investigate the internal barriers to innovation faced by SMEs in the food industrial sector and their effect on product and process innovation in Lebanon. The methodology used in this study is a quantitative descripto explanatory method. A semi-structured questionnaire is employed. 311 fully completed questionnaires were collected. The study covers an existing gap in the literature on the barriers to innovation in the Lebanese industrial sector since no previous similar studies have been conducted in the country. The empirical analysis showed that not all the internal barriers found in literature are encountered by the Lebanese SMEs.

Keywords: Small and medium-sized enterprises, product innovation, process innovation, internal barriers, Lebanese Food industry

DOI: $10.7176 / \mathrm{EJBM} / 11-30-02$

Publication date:October $31^{\text {st }} 2019$

\section{Introduction}

The economic environment has been changing rapidly and continuously. It has become more complicated due to globalization, wide extension of data and knowledge, in addition to the enormous rate of technological development. These factors have caused significant changes that have complicated the competitive environment. This urged most firms of all sizes to innovate and launch new developed services and products to meet the demand in the competitive markets (Cordeiro and Viera 2012). Innovation became a necessity for firms to maintain competitive positions in the market. All sectors have been witnessing innovation, but higher involvement has been noticed in the industrial sector (Concepcion 2016).
\end{abstract}

\section{Literature review}

SMEs possess innovatory advantages. They are capable of reacting rapidly to customers' needs and are recognized for being less bureaucratic in comparison to large firms. In general communication in SMEs is informal and they can adapt to shifts in the external environment (Rothwell \& Dodgson 1991). However, SMEs lack proficient specialists and face difficulties in borrowing capital. Though SMEs face several barriers to innovation, most manufacturing SMEs undergo product and process innovation (Woschke et al. 2017; Concepcion 2016; Amara et al. 2008). Based on that, the study will focus on product and process innovation within SMEs in the Lebanese food industrial sector.

\subsection{Innovation}

The inability to innovate and adapt quickly to the needs and demands of changing markets has led many firms like Polaroid to bankruptcy (Poutanen et al. 2016). Innovation has been given several definitions. The first definition was introduced by Joseph Schumpeter in year 1934 who specified five conditions of innovation: launching of a brand new good or to a certain new feature of a good, a brand new procedure of production, entering a new market, the acquisition of a new origin of stock or raw material, or the implementation of a new corporation of some industry (Schumpeter 2012). His definition was followed by several definitions of many scholars through the following years (Mohr 1969; Damanpour \& Evan 1984; Damanpour 1991;Lumpkin \& Dess 1996; Boer and During 2001; Pittaway et al. 2004; McAdam et al. 2007; Baregheh et al.2009; Demirbas 2011). Recently Coffin and Mitchell (2017) defined innovation as "any novel product, service, or production process that departs significantly from prior product, service, or production process architectures.” (McKinley et al. 2014, p 91)

\subsection{Small and Medium-sized enterprises (SMES)}

Worldwide SMEs represent the vast majority of firms. They play a major role especially in employing a great share of the workforce (Demirbas, 2011). In Lebanon SMEs constitute 97\% of the total Lebanese enterprises and employ more than $51 \%$ of the total workforce (El Khoury, 2013). According to the ministry of economy and trade in Lebanon (MOET), micro enterprises are enterprises with an annual turnover which is less than LBP 500 million and a number of employees which is less than 10. Small enterprises are enterprises with an annual turnover that is less than LBP 5 billion and a number of employees which is less than 50. While medium enterprises are enterprises with an annual turnover that is less than LBP 25 billion and a number of employees which is less than 50 ( El Khoury, 2015). Although SMEs face greater barriers to innovation than larger firms do, their ability to innovate is essential for gaining a competitive advantage in the developing markets (Nicks and Santamaria, 2009). 


\subsection{Types of Innovation}

Different typologies have been stated in innovation literature. Damanpour (1991) classified innovation into three pairs of types: administrative innovation-technical innovation, product innovation-process innovation, and radical innovation-incremental innovation. However in the Oslo manual (OECD, 2005) innovation is divided into four types:

- Marketing innovation: involves the implementation of advanced marketing strategies and considerable transformations in design and packaging.

- Organizational innovation: engages with the utilization of brand new methods to control perpetual activities and operations for supervising labor.

- Product innovation: involves launching a new or developed product or service.

- Process innovation: involves applying developed new approaches and methods of production or in delivery.

Among these different types of innovation, product and process innovation are the most applied in the industrial sector (Amara et al.2008).

\subsection{Barriers to innovation}

Many types of barriers to innovation have been identified in the current literature and have different classifications. Oslo manual classified them into economic barriers, firm related barriers and legal barriers. (OECD 2005). Cohen and Levinthal (1990) divided them into external and internal barriers. Although innovation has been faced by both internal and external barriers, the internal factors were the most significant barriers described by previous studies (Lukjanska 2010; Strenberg \& Arndt 2001; Madeira et al. 2017). Based on that, this study will tackle the internal barriers to product and process innovation within SMEs in the Lebanese industrial sector.

\section{Theoretical background and Hypothesis building}

According to Concepcion (2016), failing to create new knowledge internally is a major barrier to innovation. Other studies also added that firms need to possess adequate knowledge so that they have the ability to innovate (Bigliardi and Durmio 2009; Mohnen et al. 2008). This leads to the following hypotheses.

H1: failure in creating new knowledge negatively affects product innovation.

H9: failure in creating new knowledge negatively affects process innovation.

Another internal barrier that hampers innovation according to previous studies is the absence of skilled employees (Frenkel 2001). Demirbas et al. (2011) agreed that the deprivation of qualified personnel and skillful employees stops innovation in manufacturing SMEs. Avermante et al. (2004) argued that there exists a significant relation between innovation in food firms and the availability of qualified managerial and technical employees. Lack of skilled human resources stops innovation (Bigliardi and Durmio 2009; Martinez and Briz 2000). Accordingly, the following hypotheses were concluded:

H2: Absence of skilled employees negatively affects product innovation.

H10: Absence of skilled employees negatively affects process innovation.

Shortage in financial resources was considered by several scholars an important barrier to innovation. Martinez and Briz (2000) considered shortage in financial and economic capabilities as a significant barrier to innovation in Spanish food industries. Limited financial means hamper mostly radical innovation and stops new projects from beginning or reduces their speed (Demirbas et al. 2011). This introduces the following hypotheses.

H3: Scarcity of financial resources negatively affects product innovation.

H11: Scarcity of financial resources negatively affects process innovation.

Another obstacle that faces innovating firms is the excessive cost of innovation. It has been distinguished among the most important barriers in Spanish food firms that have implemented product and process innovation (Martinez and Briz 2000). Martino and Magnotti (2017) agreed also that Italian Food SMEs that have undergone product and process innovation faced uncontrollable costs. These excessive unmanageable costs have considerably affected the propensity of the industrial sector SMEs to innovate (Demirbas et al. 2011; Frenkel 2001). Moreover, Bigliardi and Durmio (2009) stated that process innovation is very costly. This introduced the following hypotheses:

H4: High uncontrollable cost negatively affects product innovation.

H12: High uncontrollable cost negatively affects process innovation

Many scholars have noted that one of the disadvantages of innovation is its excessive riskiness. Customers may not find the advanced products favorable and may reject them. Moreover, employees may also reject the implementation of new procedures and technologies at work. In addition to the fact that SMEs have limited financial recourses and their ability to diversify their investments is limited (Mohnen et al. 2008; Bigliardi and 
Durmio 2009). This abundant risk is considered a crucial barrier to innovation. According to Martinez and Briz (2000), food industrial firms that applied product and process innovation faced obstacles like risk and uncertainty. Moreover, Frenkel (2001) stated that high risk is the number one barrier resulting from innovation's soaring cost. This leads to the following hypotheses:

H5: High risk negatively affects product innovation.

H13: High risk negatively affects process innovation.

Other barriers are also detected in the literature of innovation. The ability of staff to learn and understand advanced techniques in production and to grasp new processes at work effects innovation (Amara et al. 2008). Therefore decreased learning potentials are a barrier to product and process innovation (Bigliardi and Durmio 2009). This leads to the following hypotheses as well:

H6: decreased learning potentials negatively affect product innovation.

H14: decreased learning potential negatively affect process innovation.

To improve innovation, investment in R\&D and learning is necessary. According to McAdam et al.(2017) developing and educating human capital is essential for product innovation. Fortuin and Omta (2009), argued that process innovation would be more efficient if SMEs invest in R\&D and in teaching their staff the "know -how" needed at work. Other scholars added that insufficient expenditure in training and learning-by-searching stops manufacturing firms from innovating (Amara et al. 2008; Hadjumanolis 1998). Innovation in SMEs requires effective and implied learning (Humphrey et al. 2005). This leads to the following hypotheses:

H7: decreased investment in learning negatively affects product innovation.

H15: decreased investment in learning negatively affects process innovation.

In addition to the preceding internal barriers, other scholars added that unavailability of external partners is also one of the barriers to product and process innovation. (Fortuin and Omta 2009; Nicks and Santamaria; Macadam et al.2007; Martinez and Briz 2000). Based on that, this study added the following hypothesis:

H8: unavailability of external partners negatively affects product innovation.

H16: unavailability of external partners negatively affects process innovation.

The model of internal barriers affecting product and process innovation is shown in figure 1 at the end of this paper.

\section{Methodology}

4.1 Research design and sampling

The research design adopted in this study is a descripto-explanatory design which combines explanatory and descriptive research design methods. The chosen population for the study is the SMEs of the industrial sector in Lebanon. This sector was chosen because of its immense engagement in innovation in comparison to other sectors (Concepcion 2016). Four thousand thirty three (4033) enterprises constitute the Lebanese industrial sector. This sector in Lebanon consists of 10 sub sectors. The food and beverages sub sector constitutes the biggest portion (23\%). It consists of 963 companies but the officially registered ones are 736 (Chlouk 2016). The majority of these firms are family firms employing an average of 6 workers (IDAL 2016).

The objective of this research is to investigate the barriers affecting innovation in the SMEs within the food sector only. Though SMEs constitute $97 \%$ of the total number of Lebanese enterprises (El Khoury 2015), it is important to point out that there isn't any valid research indicating the percentage of food SMEs within the population. Depending on the population of the study, the sampling frame has been constructed. The sample has been selected thoroughly to insure that the representation of SMEs is good with respect to the target population. Stratified random sampling is the appropriate sampling design selected for this study based on the clustered nature of SMES in Lebanon (IDAL 2016). The value of the sample size was determined using a statistical approach and has been found to be equal to 260. Accordingly the study intended to gather about 300 respondents. In order to connect with the respondents, a list of contacts was obtained from the ministry of industry and the chambers of commerce, industry and agriculture in Lebanon. 700 emails were sent to the targeted SMEs followed by phone calls to make the process faster and more effective. The collection process was completed within 4 weeks were the number of respondents reached 311, which matches the targeted sample size and is sufficient to build upon and deduce the necessary findings and conclusion.

\subsection{Sources of data and data collection instruments}

The methodology used in this research is quantitative using a semi-structured questionnaire. Primary data was collected from the Lebanese enterprises to reach the required objective. The questionnaire was divided into three main parts. The first part included questions about the firm's characteristics and bio-data, while the second part focused on collecting information on the firm's innovational activities (Coad et al. 2015; López-Fernández et al. 
2016), and the third part focused on collecting data related to the barriers faced by firms and its effect. The questionnaire was self-administered and sent through emails to the mangers/owners of food firms in different regions in Lebanon where these firms are located. The majority of food firms are found in Mount Lebanon (34\%) and Bekaa (30\%), followed by South Lebanon (14\%), North Lebanon (10\%), Beirut (8\%) and finally, Nabatieh (4\%) (IDAL 2016). Collected data was reviewed, uncompleted questionnaires were removed, then data was analysed using the SPSS statistical software.

\subsection{Validity and reliability of the research instrument.}

The questionnaire used in this study underwent a validation process. Samples of the questionnaire were checked and reviewed by recognized managers and owners of SMEs in the industrial sector. The questionnaire was inspected rigorously with the support of experts to make sure that this instrument is relevant, convenient, and acceptable. Accordingly few modifications were made and corrected after which a pilot test was made. This test showed few areas which required adjustments.

Moreover, to test the reliability of this questionnaire, Cronbach's alpha coefficient has been determined. It scored 0.886. According to Kothari et al. (2005) the instrument is considered reliable if the value of alpha is greater than 0.5. However, Field (2009) claimed that the value of alpha should be above 0.7 to reflect reliability. Based on that and since the result for Cronbach's alpha in this study is 0.886 , the findings of this study are considered reliable.

\section{Findings and conclusion}

Based on the regression and correlation analysis listed in table 2 inserted at the end of this paper, we rejected hypotheses (H3, H5, H8, H13, and H16). Consequently, the study findings, namely, the significant internal barriers to product and process innovation in the Lebanese industrial SMES in general and food SMEs in particular are listed in table 1 inserted at the end of this paper.

Failure in creating new knowledge negatively affects product and process innovation in the Lebanese food SMEs. This conclusion agrees with previous studies (Concepcion et al. 2016; Mohnen et al. 2008; Bigliardi and Durmio 2009), that showed similar results. The Lebanese SMEs suffer from decreased power of learning new knowledge and weak internal abilities of generating knowledge which stand as a barrier to product and process innovation. Lebanese firms should own sufficient knowledge by enhancing their learning capabilities in order to have the ability to initiate new knowledge. This would help Lebanese SMEs in using their internal resources in product and process innovation.

Absence of skilled employees negatively affects product and process innovation and is a barrier to both types of innovation in the Lebanese food SMEs. This means that SMEs in the Lebanese industrial sector are suffering from lack of skillful employees and qualified personnel. Although the majority of Lebanese people are very educated, Lebanese SMEs are facing a gap resulting from what is taught in universities and what skills businesses really require (El Khoury 2013). Similarly, and based on previous studies, other counties also face absence of skillful employees as one of the internal barriers to process and product innovation (Frenkel 2000; Demirbas et al. 2011; Martinez and Briz 2000; Bigliardi and Durmio 2009; Mohnen et al. 2008)

High uncontrollable cost is found to be a barrier to both product and process innovation in the Lebanese food SMEs. These results agree with previous literature where cost has been identified as a significant barrier to innovation. (Martino and Magnotti 2017; Frenkel 2001; Martinez and Briz 2000; Demirbas et al. 2011; Bigliardi and Durmio 2009)

Scarcity of financial resources isn't found to be a barrier to product innovation in the Lebanese Food SMEs, in contrast to previous studies which noted that shortage in financial resources negatively affects innovation in the food industry (Martinez and Briz 2000), and this is a significant barrier to product innovation in the industrial sector (Galia and Legros 2002; Frenkel 2001; Woschke et al. 2017; Bigliardi and Durmio 2009; Martino and Magnotti 2017). This may be the result of the financial support which is provided by the Lebanese government to the food industrial sector in Lebanon. Other studies have found other barriers to be more relevant and to have direct impact on product innovation in the food industrial sector like the qualification of human capital (McAdam et al. 2007). However, based on our findings, scarcity of financial resources is found to negatively affect process innovation in agreement with previous studies. (Martinez and Briz; Demirbas et al.2011; Wascke et al. 2017; Bigliardi and Durmio 2009). Moreover, McAdam et al. (2007) noted that process innovation is related to a greater extent to the financial structure of the firm and food SMEs face financial barriers in process innovation.

In contrast to previous studies (Martinez and Briz 2017; Frenkel 2000; Martino and Magrotti 2017; Bigliardi and Durmio 2009; Mohnen et al. 2008), the study concluded that high risk is not found to be a barrier to product and process innovation in the Lebanese industrial sector. This result might be reached due to many possible conditions. One condition might be that the sample, even though it is sufficient to the research process, it might be small compared to the number of firms in the Lebanese industrial sector (311 out of 4033). Another reason might be the specificity of the Lebanese culture, as the majority of current studies are conducted in other countries. 
Process and product innovation are found to be negatively affected by the decreased learning abilities of staff in the Lebanese food SMEs. Decreased learning potential is a barrier to innovation similar to previous studies (Amara et al. 2008; Bigliardi and Durmio 2009). This may be due to the fact that the qualifications of staff do not conform to the requirements needed to grab process and product innovation in Lebanese SMEs because the educational system in the Lebanese universities recently introduced innovation concepts to its curriculum. Moreover, the culture doesn't encourage young people to be entrepreneurs (Schellen 2016). Based on the above findings, we came up with the following regression equations:

$\mathrm{PtI}=0.129+0.511 \mathrm{~K}+0.163 \mathrm{E}-0.078 \mathrm{C}-0.192 \mathrm{~L}+0.298 \mathrm{I}$

PsI $=0.096+0.570 \mathrm{~K}+0.430 \mathrm{E}+0.158 \mathrm{~F}-0.136 \mathrm{C}-0.059 \mathrm{~L}+0.177 \mathrm{I}$

\section{Limitations and future recommendations}

The present research study has numerous limitations encountered by the author and which might be taken into consideration in forthcoming studies. The research design of the study is cross-sectional, although a longitudinal research design is recommended. In addition, the research study specifically examined the industrial sector in Lebanon. Subsequently, an expansive research study population and industry could provide new insights and understanding into the investigated concepts. Other limitations included the fact that several questionnaire recipients did not reply or take part in the research.

Upon conducting the research, the author faced issues in finding rich databases and references about this particular topic in Lebanon. No similar researches have been conducted within this region, in addition to the lack of official databases needed for the completion of the research. Finally, the author personally funded the research. As for future recommendations, similar studies should be conducted in different sectors in Lebanon to further enrich the literature of innovation. In addition, other studies should cover other aspects of the literature of innovation in Lebanon, such as external barriers.

\section{References}

Amara, N. et al. (2008). Learning and novelty innovation in established manufacturing SMEs. Technovation, 28, 450-463.

Baregheh, A. and Rowley, J. and Sambrook, S. (2005). Towards a multidisciplinary definition of innovation. Management Decision, 47, 1323-1339.

Bigliardi, B. and Durmio, A. (2009). An empirical investigation of innovation determinants in food machinery enterprises, European journal of innovation management, 12(2), 223-242.

Boer, H. and Duringo, W. (2001). Innovation. What Innovation? A comparison between product, process and organizational innovation. International Journals of Technology Management, 22, 83-107.

Chlouk, G., (2016). Economic Opportunities and Job Creation: Tourism Sector Draft for Discussion. Available at:

$<$ http://www.databank.com.lb/docs/Economic\%20Opportunities\%20and\%20Job\%20Creation\%20in\%20To urism\%20Section\%202016\%20UN.pdf> [Accessed 26 September 2019].

Coad, L., Leverington, F., Knights, K., Geldmann, J., Eassom, A., Kapos, V., ... \& Nolte, C. (2015). Measuring impact of protected area management interventions: current and future use of the Global Database of Protected Area Management Effectiveness. Philosophical Transactions of the Royal Society B: Biological Sciences, 370(1681), 20140281.

Coffin, K. and Mitchell, R. (2017). The innovation management. England: Palgrave.

Cohen, W. M, and Levithal, D. A. (1990). Absorptive capacity: a new perspective on learning and innovation. Administrative science quarterly, 35(1), 128-152.

Concepcion, M. et al. (2016). What hampers innovation in Mexican financing firms? Academia Revista Latino America de Administracion, 29(3), 255-278.

Cordeiro, A. \& Vieira, F., 2012. Barriers to innovation amongst small and medium-sized enterprises (SMEs) in Portugal. University of Minho, Guimarães, Portugal.

Damanpour, F. (1991). Organizational Innovation: A Meta-Analysis of Effects of Determinants and Moderators. The Academy of Management, 4, 555-590.

Damanpour, F. and Evan, W. (1984). Organizational Innovation and Performance: The Problem of "Organizational Lag”. Administrative Science Quarterly, 29, 392-409.

De Martino, M. and Magrotti, F. (2017). The innovation capability of small food firms in Italy. European journal of innovation management. Retrieved from: https://doi.org/10.1108/EJiM-04-2017-0041

Demirbas, D. (2011). How do entrepreneurs perceive barriers to innovation? Imperial evidence from Turkish SMEs, World business institute Australia. Retrieved from: http://nrl.northumbria.ac.uk/8432/

Demirbas, D. (2011). Owner manager's perceptions of barriers to innovation: Empirical evidence from Turkish SMEs. Journal of Small Business and Enterprise Development, 18, 764-780.

El Khoury, Z. (2015). Lebanon SME strategy: a roadmap to 2020. MOET. Retrieved from: 
https://www.economy.gov.lb/public/uploads/files/8618-1911-5908.pdf

El Khoury, Z. (2013). Overview of the SME sector in Lebanon and the role of the ebteoreuse tean at ministry of economy trade. MOET. Retrieved from: https://www.economy.gov.lb/public/uploads/files/3342-74782485.pdf.

Field, A. (2009). Discovering Statistics Using SPSS, Third Edition.

Fortuin, F. and Omta, O. (2009). Innovation drivers and barriers in food processing. British food journal, 111(8), 839-851.

Frenkel, A. (2001). Barriers and limitations in the development of industrial innovation in the region. European planning studies, 1-29.

Frenkel, A. (2001).barriers and limitations in the development of industrial innovation in the region. European Planning Studies, 126.

Galia, F. and Legros, D. (2002). Complementary between obstacles to innovation: empirical study on a french data set. Research policy, 33(8), 1185-1199

Hadjumanolis, A. (1998). Barriers to innovation for SMEs in a small less developed country (Cyprus), Technovation, 19, 561-570.

IDAL (2016). Investment opportunities in the Agro food sector. Investinlebanon.gov.lb

Kothari, S. P., A. J. Leone, and C. Wasley. 2005. Performance matched discretionary accrual measures. Journal of Accounting and Economics 39 (1): 163-197.

López-Fernández, M. C., Serrano-Bedia, A. M., \& Palma-Ruiz, M. (2016). What hampers innovation in Mexican family firms?. Academia Revista Latinoamericana de Administración, 29(3), 255-278.

Lukjanska, R. (2010). Internal and external innovation hindering obstacles at SME. In International Scientific Conference BMRA.

Lumpkin, G. and Dess, G. (1996). Clarifying the entrepreneurial orientation construct and linking it to performing. The Academy of Management, 21,, 135-172.

Madeira, M. J., Carvalho, J., Moreira, J. R. M., Duarte, F. A., \& de São Pedro Filho, F. (2017). Barriers to innovation and the innovative performance of Portuguese firms. Journal of Business, Universidad del Pacífico (Lima, Perú), 9(1), 2-22.

McKinley, W., Latham, S., \& Braun, M. (2014). Organizational decline and innovation: Turnarounds and downward spirals. Academy of Management Review, 39, 88-110.

Martinez, M. and Briz, J. (2000). Innovation in the Spanish food and drink industry. International food and agribusiness management review, 3, 155-176.

McAdam, R. and Renee, W. and Mitchell, R. (2007). Implementing Innovation Management in Manufacturing SMEs: a longitudinal study. Journal of Small Business and Enterprise Development, 14, 385-403.

Mohnen, P. et al. (2008). Financial constraints and other obstacles: are they a threat to innovation activity: de economist, 156(2), 201-214

Mohr, L. (1969). Determinants of Innovation in Organizations. The American Political Science Review, 63, 111126.

Nicks, M. and Santamaria, L. (2009). Technological collaboration: bridging the innovation gap between small and large firms. Research policy, 38(3), 507-517.

OECD. (2005). Oslo manual guidelines for collecting and interpreting innovation data.

Pittaway, L. et al. (2004). Networking and Innovation, a systematic review of the evidence. International Journal of Management Reviews, 5, 137-168.

Poutanen, P. and Soliman, W. and Stahle, P. (2016). The complexity of innovation: an assessment and review of the complexity perspective. European journal of innovation management, 9(2), 189-213

Rothwell, R. and Dodgon, M. (1991). External linkages and innovation in small and medium sized enterprises. R\&D management.

Schumpter, J. (2012). The Theory of Economic Development : An Inquiry into profits, capital, credit, interest, and the business cycle. New Brunswick (USA) and London (U.K): Transaction Publishers.

Schellen, T. (2016). Boldly adding academia to the entrepreneurship game plan. Executive. https://www.executive-magazine.com/entrepreneurship/into-a-new-dimension

Sternberg, R. and Arndt, O. (2001), "The firm or the region: what determines the innovation behavior of European firms?", Economic Geography, Vol. 77 No. 4, pp. 364-82.

Woschke, T. and Haasse, H. and Kratzer, J. (2017). Resources scarcity in SMEs: Effects on incremental and radical innovations. Management research review, 40(2), 195-217. 


\begin{tabular}{|c|c|}
\hline Barriers to product innovation: & Barriers to process innovation: \\
\hline - Failure in creating new knowledge & - $\quad$ Failure in creating new knowledge \\
\hline - $\quad$ Absence of skilled employees & - $\quad$ Absence of skilled employees \\
\hline - High uncontrollable cost & - Scarcity of financial resources \\
\hline - $\quad$ Decreased learning potentials & - $\quad$ High uncontrollable cost \\
\hline - $\quad$ Decreased investment in learning. & - $\quad$ Decreased learning potentials \\
\hline & - $\quad$ Decreased investment in learning \\
\hline
\end{tabular}

Table 1: Barriers to Product and Process Innovation in Lebanon

\begin{tabular}{|c|c|c|c|c|c|c|c|c|c|c|}
\hline Dependent & \multicolumn{5}{|c|}{ Product innovation (PtI) } & \multicolumn{5}{|c|}{ Process innovation(PsI) } \\
\hline & Correlati & test & & ressio & test & Correlati & test & $\operatorname{Re}$ & ressio & est \\
\hline $\begin{array}{l}\text { Independent } \\
\text { variables }\end{array}$ & $\begin{array}{c}\text { Pearson } \\
\text { Correlatio } \\
\mathbf{n} \\
\end{array}$ & Sig. & Coef & Sig. & $\mathbf{R}^{2}$ & $\begin{array}{c}\text { Correlatio } \\
\text { n }\end{array}$ & Sig. & $\begin{array}{c}\text { Coef } \\
.\end{array}$ & Sig. & $\mathbf{R}^{2}$ \\
\hline $\begin{array}{l}\text { Failure in } \\
\text { creating new } \\
\text { knowledge } \\
(\mathrm{K})\end{array}$ & 0.543 & $\begin{array}{l}0.00 \\
0\end{array}$ & $\begin{array}{l}0.51 \\
1\end{array}$ & $\begin{array}{l}0.00 \\
9\end{array}$ & \multirow{5}{*}{$\begin{array}{l}0.47 \\
9\end{array}$} & 0.547 & $\begin{array}{l}0.00 \\
0\end{array}$ & $\begin{array}{l}0.57 \\
0\end{array}$ & $\begin{array}{l}0.00 \\
0\end{array}$ & \multirow{5}{*}{$\begin{array}{l}0.59 \\
0\end{array}$} \\
\hline $\begin{array}{l}\text { Absence of } \\
\text { skilled } \\
\text { employees(E) }\end{array}$ & 0.434 & $\begin{array}{l}0.00 \\
0\end{array}$ & $\begin{array}{l}0.16 \\
3\end{array}$ & $\begin{array}{l}0.00 \\
7\end{array}$ & & 0.622 & $\begin{array}{l}0.00 \\
0\end{array}$ & $\begin{array}{l}0.43 \\
0\end{array}$ & $\begin{array}{l}0.00 \\
0\end{array}$ & \\
\hline $\begin{array}{l}\text { High } \\
\text { uncontrollabl } \\
\text { e } \operatorname{cost}(\mathrm{C})\end{array}$ & -0.159 & $\begin{array}{l}0.00 \\
6\end{array}$ & $\begin{array}{l}- \\
0.07 \\
8 \\
\end{array}$ & $\begin{array}{l}0.00 \\
6\end{array}$ & & -0.162 & $\begin{array}{l}0.00 \\
5\end{array}$ & $\begin{array}{l}- \\
0.13 \\
6\end{array}$ & $\begin{array}{l}0.02 \\
3\end{array}$ & \\
\hline $\begin{array}{l}\text { Decreased } \\
\text { learning } \\
\text { potentials }(\mathrm{L})\end{array}$ & -0.352 & $\begin{array}{l}0.00 \\
0\end{array}$ & $\begin{array}{l}- \\
0.19 \\
2 \\
\end{array}$ & $\begin{array}{l}0.00 \\
2\end{array}$ & & -0.284 & $\begin{array}{l}0.00 \\
0\end{array}$ & $\begin{array}{l}- \\
0.05 \\
9\end{array}$ & $\begin{array}{l}0.03 \\
0\end{array}$ & \\
\hline $\begin{array}{l}\text { Decreased } \\
\text { investment in } \\
\text { learning(I) }\end{array}$ & 0.222 & $\begin{array}{l}0.00 \\
0\end{array}$ & $\begin{array}{l}0.29 \\
8\end{array}$ & $\begin{array}{l}0.00 \\
0\end{array}$ & & 0.244 & $\begin{array}{l}0.00 \\
0\end{array}$ & $\begin{array}{l}0.17 \\
7\end{array}$ & $\begin{array}{l}0.00 \\
3\end{array}$ & \\
\hline $\begin{array}{ll}\text { Scarcity of } \\
\text { financial } \\
\text { resources }\end{array}$ & 0.524 & $\begin{array}{l}0.00 \\
0\end{array}$ & - & - & & 0.571 & $\begin{array}{l}0.00 \\
0\end{array}$ & $\begin{array}{l}0.15 \\
8\end{array}$ & $\begin{array}{l}0.00 \\
8\end{array}$ & \\
\hline
\end{tabular}

Table 2: Statistical Results of Regression and Correlatrion Tests For Significant Variables

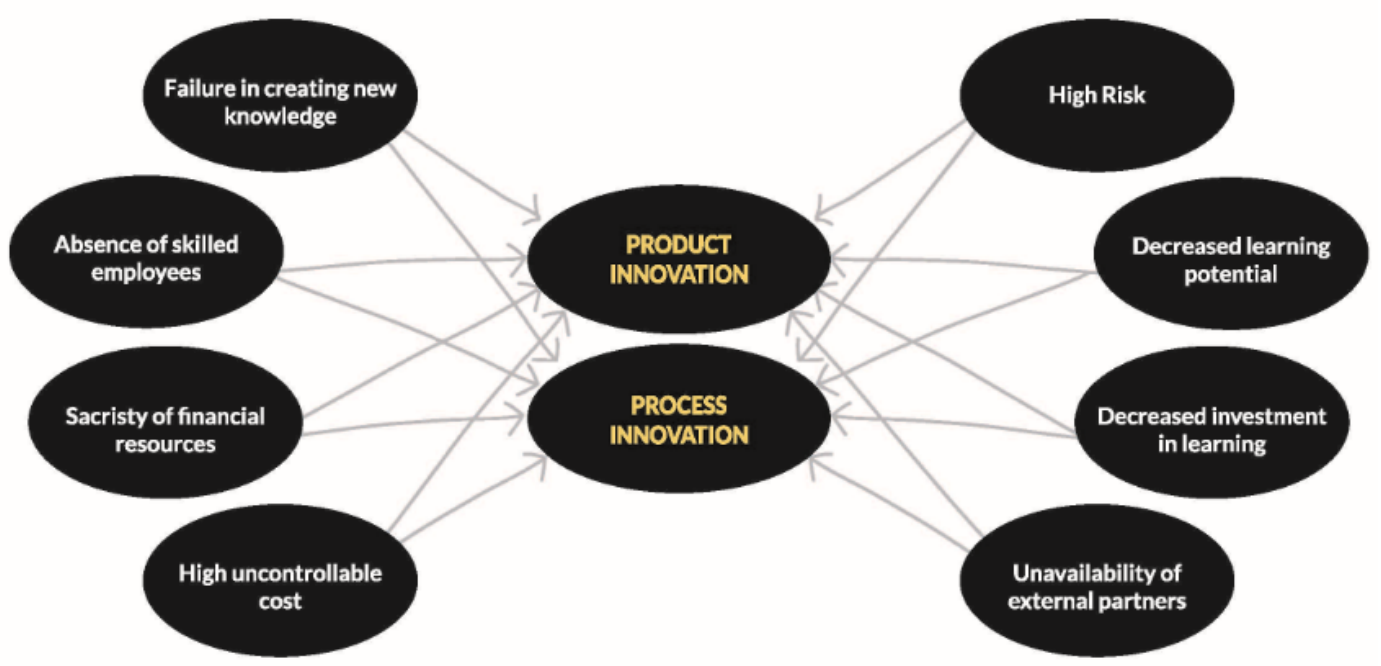

Figure 1: Internal Barriers Affecting Product and Process Innovation 